\title{
Exaltar a tradição e ser contemporâneo:
} a conversão do estigma em emblema no batuku de Cabo Verde

\section{GLÁUCIA APARECIDA NOGUEIRA*}

RESUMO: Jovens artistas da ilha de Santiago (Cabo Verde, África Ocidental) são representantes daquilo que se poderia chamar uma vanguarda musical cabo-verdiana. Inseridos em contextos de produção urbanos, ocidentais e contemporâneos, reelaboram o batuku, um género musical rural, a partir da transposição do seu ritmo para instrumentos e padrões próprios da produção musical urbana contemporânea. Ao mesmo tempo, voltam-se para temáticas em que predomina o imaginário rural-tradicional. As suas composições exaltam as características e vivências do badiu, em particular o badiu di fora, habitante do interior da ilha, outrora estigmatizado e mesmo hoje vítima de algum preconceito pelos da capital. Como uma paradoxal vanguarda que olhe para trás, a contemporaneidade musical em Cabo Verde caracteriza-se por se equilibrar entre o rural e o urbano, de alguma forma mesclando-os, sem que nisso haja contradição. Através das trajetórias de alguns desses artistas e suas letras, mostra-se essa atitude, deixando em aberto pistas para reflexão sobre as suas motivações.

Palavras-chave: Música popular; Cabo Verde; batuku; contemporaneidade; ruralidade.

\section{Celebrating tradition while being contemporary: the conversion of stigma into an emblem in Cabo-Verdean Batuku music}

\begin{abstract}
Young artists from Santiago are representatives of what could be termed a Cabo-Verdean musical vanguard. Immersed in contexts which are by turns urban, western and contemporary, they are re-elaborating Batuku by transposing its rhythms for instruments and contexts belonging to contemporary urban musical production. At the same time, they are interested in themes in which rural-traditional imagery predominate. Their compositions celebrate the characteristics and way of life of the Badiu, especially the Badiu di fora - the people who live in the interior of the island of Santiago, stigmatised in earlier times, and who even today are the victim of prejudice by people from the capital, Praia. As a paradoxical vanguard looking backwards, the contemporary music scene in Cabo Verde is characterised by balancing itself between the rural and the urban, to some extent mixing them, without feeling them incongruent. This attitude of the musicians is revealed by examining the artistic careers of a number of them and the songs they have written, while leaving open a number of different pathways of interpretation for their motives.
\end{abstract}

Keywords: Popular music; Cabo Verde; Batuku; contemporary culture; rural life.

\footnotetext{
* Gláucia Aparecida Nogueira é Doutoranda em Patrimónios de Influência Portuguesa, vertente Estudos Culturais; Mestre em Património e Desenvolvimento; Graduada em Antropologia e Comunicação Social. Pesquisa em etnomusicologia. E-mail: glaucia.nog@gmail.com

NOGUEIRA, G. A. Exaltar a tradição e ser contemporâneo: a conversão do estigma em emblema no batuku de Cabo Verde. Música Popular em Revista, Campinas, ano 6, v. 1, p. 185-206, jan.jul. 2019.
} 
República de Cabo Verde, ao completar em 2015 o $40^{\circ}$ aniversário da sua
independência de Portugal, apresenta um cenário musical bastante
diversificado, em que se destacam compositores/intérpretes inseridos na linha de reelaboração do batuku¹, embora alguns deles pratiquem também outros géneros musicais, com destaque para o funaná ${ }^{2}$. O batuku, na sua versão tradicional baseado em percussão e voz, no padrão canto-resposta e praticado sobretudo por mulheres (cf. HURLEY-GLOWA,1997; SEMEDO, 2009; RIBEIRO, 2012), passou a ser valorizado a partir da independência, contrariando o menosprezo de que era alvo no período colonial, enquanto música de escravos, mais tarde dos camponeses e das pessoas da classe baixa de modo geral, tendo sido reprimido tanto pela administração colonial como pela Igreja Católica (NOGUEIRA, 2015, p. 73-77).

Na fase pós-independência, passa a aparecer em comícios, festivais, saraus culturais e ações de conscientização, como fica evidente pela imprensa da época (cf. NOGUEIRA, 2015, p. 80-83); é objeto de recolhas, como as realizadas por Tomé Varela da Silva, das letras de cantigas de finason ${ }^{3}$ de Nha Nácia Gomi, Nha Gida Mendi e Nha Bibinha Cabral, que resultaram em livros publicados (cf. SILVA, 1988a, 1988b, 1990); e é tema de artigos que lhe atribuem estatuto de “ato de cultura" (DUARTE, 1982, p. 7-8) e expressão de orgulho nacional e património cultural (DELGADO, 2009, p. 17).

\footnotetext{
${ }^{1}$ Utilizo a grafia batuku - segundo o Alfabeto Unificado para a Escrita do Cabo-Verdiano (Alupec) - e não batuque para especificar que se trata da música associada à ilha de Santiago de Cabo Verde, excluindo outras expressões musicais identificadas como batuque que se podem encontrar em outros países da África ou no Brasil.

${ }^{2}$ Funaná: género musical com origem no meio rural da ilha de Santiago que na década de 1980 foi resgatado da sua condição periférica de música de camponeses pelo grupo Bulimundo (cf. KATCHÁS, Tribuna, dez. 1983: 13), que o adaptou aos instrumentos elétricos tornando-o uma música urbana e contemporânea. Seguiu-se um boom discográfico baseado nesse género musical. Embora algumas questões que se verificam no batuku possam também ser afirmadas para o funaná, não são aprofundadas neste artigo, considerando que ao longo do tempo, e em particular no momento em que se escreve este texto, ocorrem novos processos de transformação (cf. NOGUEIRA; BANGO, 2013) que requerem uma análise específica sobre esta expressão musical, ainda que em alguns contextos elas apareçam interligadas.

${ }^{3}$ Finason: cantigas baseadas em máximas, ditados e provérbios, são improvisadas num determinado momento da sessão de batuku. Nem todas as batukaderas o praticam. Hoje praticamente desapareceu, tendendo a passar da oralidade para a forma escrita, a partir da iniciativa do compositor Princezito, que em 2015 publicou Antigu Pensamentu, obra composta por "poemas-finason". Para Hurley-Glowa (1997, p. 5), o finason é "primariamente um género de poesia oral, mais que um género musical".

NOGUEIRA, G. A. Exaltar a tradição e ser contemporâneo: a conversão do estigma em emblema no batuku de Cabo Verde. Música Popular em Revista, Campinas, ano 6, v. 1, p. 185-206, jan.jul. 2019.
} 
Num segundo momento, a partir de finais da década de 1990, e mais intensamente a partir de 2000, o trabalho sobre os padrões rítmicos do batuku por parte de uma geração de músicos então emergente apresentou-se como uma forte tendência dentro do cenário musical cabo-verdiano, conquistando sucesso de público e de crítica $^{4}$ e despertando o interesse de produtores com inserção em mercados internacionais, o que levou a música desses artistas a públicos bem mais amplos que aqueles cingidos às comunidades cabo-verdianas emigradas. Casos, por exemplo, de Orlando Pantera, Tcheka, Princezito, Vadú, Mayra Andrade, Lura e Élida Almeida (esta última iniciando a sua carreira bem mais tarde, em 2014), nomes que serão referidos ao longo deste artigo.

Tratando-se de artistas que estão em perfeita sintonia com as práticas musicais contemporâneas urbanas e internacionais, é interessante notar um elemento presente nas letras das composições de todos eles e, embora não exclusivamente, de forma muito intensa: a temática voltada para o rural/tradicional, em que comparecem os hábitos e dramas do camponês, suas vicissitudes e alegrias, a moralidade, crenças e tradições, entre outros aspetos. Tal situação é evidente também para Rui Cidra, que constata logo à partida na sua tese com foco no funaná:

\begin{abstract}
Práticas expressivas, rituais ou formulações de crioulo atribuídas às populações do interior da ilha de Santiago constituem, desde o período da Independência Nacional, uma fonte de inspiração para os processos de criatividade desenvolvidos por jovens músicos com uma ligação biográfica a esse contexto. Mais do que uma categoria restrita de localização espacial, o "interior" (em crioulo fora) é uma construção cultural que denota uma história e uma memória social distintivas no contexto cabo-verdiano, assim como conceções de "origem" da sociedade crioula cabo-verdiana, de ancestralidade e de autenticidade cultural. (CIDRA, 2011, p. 6)
\end{abstract}

Este autor observou na cidade da Praia no início da década de 2000 como jovens da Praia, "com ténues ligações ao interior mas convivendo com imagens românticas de ser badiu ${ }^{5}$, desenvolvidas após a Independência, formulam 'novas' identidades badiu", as quais se traduzem em estilos de vida, aparência (em

\footnotetext{
${ }^{4}$ Não existindo nos órgãos de comunicação em Cabo Verde secções especializadas em crítica musical ou de outras formas de arte, nem autores que se dediquem a esse género jornalístico, considero que se pode falar em sucesso de crítica com base em artigos publicados em países onde os artistas em questão se apresentam ou onde são editados os seus discos. Portugal, França e Brasil são países onde tenho constatado pela mídia, em diferentes graus, a divulgação da música de artistas cabo-verdianos. ${ }^{5}$ Expressão que designa o habitante da ilha de Santiago, que abordarei mais detalhadamente à frente. 
particular através do uso do pano di terra no vestuário e acessórios), gostos musicais e no interesse pela história da ilha. "Ser badiu significa nestas configurações de identidade ser livre, autônomo e espontâneo" (CIDRA, 2011, p. 68).

Este artigo propõe lançar pistas para uma reflexão sobre o que leva estes compositores e intérpretes da geração que recria o batuku a comporem letras que remetem com frequência para esse imaginário rural e valores tradicionais, em grande parte eles próprios em processo de transformação face à inserção do país em redes de migrações, há já muito tempo; às lógicas da globalização e das redes das indústrias criativas; à sua exposição aos meios de comunicação e às tecnologias digitais, aspetos que fazem de Cabo Verde um espaço bastante aberto a influências estrangeiras e sintonizado com as tendências mundiais, fato que não é de hoje e que sempre se refletiu na sua música.

Sem contar, como refere Featherstone (1997, p. 164), que cidades coloniais como o Rio de Janeiro ou Calcutá foram as primeiras sociedades multirraciais e multiculturais, lista a que a podemos acrescentar a Ribeira Grande (mais conhecida localmente como Cidade Velha), a primeira cidade fundada pelos portugueses na África - em 1462.

Apesar dessa sua inserção antiga em redes que transcendem o seu território, o tradicional, as coisas típicas, ditas terra-terra na linguagem local, são bastante valorizadas em Cabo Verde, como uma garantia de autenticidade e afirmação identitária. Para compreender tal fato podemos recorrer novamente a Featherstone (1997, p. 132), quando este lembra que o "senso do lar" é "mantido pela memória coletiva, a qual depende de desempenhos rituais, práticas corporais e cerimónias comemorativas" como casamentos, enterros, o Natal, o Ano-Novo, rituais que podem ser considerados "baterias que carregam os laços emocionais entre as pessoas e renovam a consciência do sagrado".

Ainda segundo este autor,

[...] uma das maneiras pela qual o sagrado atua nas localidades está nos incontáveis pequenos rituais, ritos e cerimónias que ocorrem nas práticas entre amigos, vizinhos e associados. Os pequenos rituais implicados no pagamento de uma roda de bebidas, de uma determinada maneira, ou voltar cada semana a um bar para ocupar o mesmo lugar, ajudam a formalizar relacionamentos que cimentam os laços sociais entre as pessoas [...] a 
coordenação dos gestos e movimentos corporais que jamais foi verbalizada ou submetida à reflexão; os odores e sons familiares; a capacidade de tocar e olhar para coisas que se tornaram revestidas de simbolismo e afeto. (FEATHERSTONE, 1997, p. 133).

Voltando aos referidos artistas badiu, isto é, da ilha de Santiago, mais especificamente do interior - badiu di fora, como são identificados por oposição aos habitantes da cidade da Praia, evidenciando-se aqui uma situação de periferia e subalternidade do interior face à centralidade da cidade-capital -, é interessante observar como esse grupo procede de alguma forma a uma institucionalização positiva do estigma, como refere Bourdieu (1989, p. 125), assumindo-o e tornando-o um emblema, ao criar letras baseadas justamente nesses aspetos ligados a um mundo periférico, desvalorizado e no passado alvo verdadeiramente de estigma - a própria designação badiu vem de "vadio", como eram chamados os negros livres e libertos que viviam à margem da economia e da sociedade escravocratas. (SILVA, 1995, p. 70-71).

Por outro lado, pode-se questionar se seria essa inclinação para o rural/tradicional uma questão de mercado no contexto da world music, tendo em conta uma imagem cristalizada de Cabo Verde em que a autenticidade é fortemente ligada ao rural, tendo na agricultura, e no milho em particular, um ícone. Ou seria uma questão identitária, reveladora do quanto se sentem de fato rurais, embora inseridos em outros contextos de vida e produção musical? E o que é ser urbano ou ser rural em Cabo Verde? Sem a pretensão de chegar a respostas conclusivas, estas questões servirão, ao longo destas páginas, para procurar conhecer melhor esta faceta da contemporaneidade musical cabo-verdiana, recorrendo a autores cujos escritos, por vezes referindo-se a outros países e a outras circunstâncias, podem contribuir para uma compreensão do caso específico de Cabo Verde.

\section{Rural x urbano em Cabo Verde}

Do total de 491.683 habitantes do arquipélago de Cabo Verde, a população urbana é de 303.67, segundo o mais recente censo da população (CABO VERDE, 2010), o que significa 61,8\% das pessoas a viver nas cidades. A sua evolução, de 1980

NOGUEIRA, G. A. Exaltar a tradição e ser contemporâneo: a conversão do estigma em emblema no batuku de Cabo Verde. Música Popular em Revista, Campinas, ano 6, v. 1, p. 185-206, jan.- 
para 2010, foi de 32,5\% para 44,1\% em 1990, atingindo os 53,4\% em 2000, até chegar aos atuais 61,8\% (CABO VERDE, 2010). A população rural atual, composta por 188.010 habitantes, corresponde a 38,2\% da população, sendo que em 1980, era 67,5\% de um total de 295.703 habitantes. Na ilha de Santiago, que então tinha 145.957 habitantes, correspondia a 71\%. (FURTADO, 1993, p. 141). O êxodo rural inverteu os termos da balança entre população rural e urbana. Tal facto reflete-se nas cidades, que ganham periferias superpovoadas, onde se mantêm vivos muitos hábitos rurais. Jardins com pés de cana ou milho plantados, gado bovino e caprino pastoreado entre os automóveis pelas ruas de bairros da capital, Praia, e suínos criados em quintais ou terraços são imagens comuns, apesar das proibições formais das autoridades municipais no que diz respeito à criação de animais em áreas urbanas.

Já em 1992, a meio desse processo de êxodo para a cidade da Praia, um cronista local comentava, num texto intitulado "Rurbanos":

Da janela vejo de tudo, campo e cidade, nem uma coisa nem outra, o campo a entrar pela cidade dentro e a cidade a invadir o campo [...] Realmente somos rurbanos, pelo espaço que ocupamos, os costumes que temos e as relações que mantemos. Por outras palavras, estamos no território econômico, social, cultural e religioso inseguro, onde a cidade e o campo disputam a supremacia. (TOLENTINO, 1992, p. 2)

As mudanças nas últimas décadas nas relações das pessoas da cidade com o campo tornaram este último algo mais que um espaço de produção agrícola, ficando ultrapassada a visão dualista que opunha o rural e o urbano como realidades que se negavam uma à outra e associando o rural ao agrícola, atrasado, e o urbano ao industrial, moderno, escreve Carneiro (2014, p. 58), lembrando que por outro lado também ficou ultrapassada a ideia de que o êxodo rural, pondo em contato a população que emigra com vivências urbanas, resultaria na difusão de práticas e hábitos urbanos, fazendo com que deixasse de haver grandes diferenças entre cidade e campo. Opondo-se tanto à visão dicotómica como a esta última, de homogeneização, autores como Chamborredon (1980) e Rambaud (1969; 1981), citados por Carneiro, defendem que a integração das aldeias na economia global "ao invés de diluir as diferenças, pode propiciar o reforço de identidades apoiadas no pertencimento a uma localidade". "Essa âncora territorial seria a base sobre a qual a cultura realizaria a interação entre o rural e o urbano de um modo determinado, ou 
seja, mantendo uma lógica própria que lhe garantiria a manutenção de uma identidade", escreve Carneiro, para quem a "as transformações na comunidade rural provocadas pela intensificação das trocas com o mundo urbano (pessoais, simbólicas, materiais...) não resultam, necessariamente, na descaracterização de seu sistema social e cultural"' (CARNEIRO, 2014, p. 58).

Nesse contexto de mudanças na bipolaridade entre rural e urbano, em cenário de globalização, é interessante ter em conta o que Hall afirma sobre a tendência para a homogeneização: ao lado dela, há também um fascínio pela diferença e a tendência para a mercantilização da etnia e da alteridade. "Há, juntamente com o impacto do 'global', um novo interesse pelo 'local'. A globalização (na forma da especialização flexível e da estratégia de criação de 'nichos' de mercado), na verdade, explora a diferenciação local." (HALL, 2005 [1992], p. 77).

Segundo o mesmo autor, referindo-se à questão da identidade, as culturas nacionais são compostas não apenas de instituições culturais, mas também de símbolos e representações. Uma cultura nacional "é um discurso - um modo de construir sentidos que influencia e organiza tanto nossas ações quanto a concepção que temos de nós mesmos”. (HALL, 2005 [1992], p. 50). Quanto às formas como se tece essa narrativa, Hall seleciona vários elementos que costumam ser invocados, dos quais considero encaixar-se no tema deste artigo os seguintes: a narrativa da nação (presente nas histórias e nas literaturas nacionais, na mídia e na cultura popular, com cenários, eventos, símbolos e rituais que simbolizam ou representam experiências partilhadas); a ênfase nas origens, na continuidade, na tradição; a invenção da tradição, citando Hobsbawm e Ranger (HALL, 2005 [1992], p. 52-55).

Nessa linha, as noções de rural e de urbano, assim como a de ruralidade, "e a dualidade que lhes é intrínseca são representações sociais que expressam visões de mundo e valores distintos de acordo com o universo simbólico ao qual estão referidas, estando, portanto, sujeitas a reelaborações e a apropriações diversas", escreve Carneiro (2014, p. 60). Embora estas observações se refiram a contextos de interação rural-urbano no Brasil, podem ser aplicadas ao caso de Cabo Verde, onde muito mais intensamente o rural e o urbano estão próximos e se interpenetram, dadas as curtas distâncias geográficas aí existentes, não sendo poucas as pessoas que 
vivem no interior, a 30 ou 40 quilômetros da capital, e que diariamente se deslocam para aí trabalhar ou estudar.

\section{A temática rural e seus autores}

Em finais da década de 1990, a trabalhar em Cabo Verde, o produtor cultural português Miguel Gomes da Costa reparou que havia na cidade da Praia um movimento formado por uma nova geração de artistas que nunca tinham gravado. Faziam música "com uma raiz popular muito forte baseada nas tradições da ilha de Santiago, mas com novos instrumentos e com outras influências [parte dos músicos presentes na compilação estudou em Cuba e no Brasil]", escreve dois anos depois no jornal Sodadeonline o jornalista Tiago Luís Pedro (apud NOGUEIRA, 2015, p. 101).

Surge daí, em 2002, o álbum coletivo Ayan! - palavra que significa um "sim" convicto, na variante de Santiago da língua cabo-verdiana - com a participação de Princezito, Vadú, Tcheka e o grupo Djingo. São as primeiras gravações de quase todos eles e surgem como "uma revolução musical", nas palavras de Princezito. "Foi uma das poucas vezes na história que jovens resolvem voltar-se para a raiz ao invés de ir para música mais moderna" (PRINCEZITO, entrevista à autora, 2010).

Entre os personagens da cena musical santiaguense desse período está Orlando Pantera (1967-2001), cuja curta carreira (morreu aos 33 anos, quando se preparava para gravar aquele que seria o seu primeiro álbum), foi suficiente para que fosse consagrado como ícone desse "movimento". Nascido no interior de Santiago, Pantera migrou com a família para Angola, tendo regressado a Cabo Verde com cerca de dez anos. No início da década de 1990, ensina música na escola Pentagrama, na Praia, e no Centro Juvenil de Assomada (município de Santa Catarina, interior de Santiago), onde foi também coordenador artístico da Aldeia Infantil SOS. Integra em meados da década, como baixista, o Pentágono, grupo que gravou no seu único disco, de 1994, algumas- músicas suas (zouks ${ }^{6}$ e colazouks ${ }^{7}$, mostrando que se ${ }^{6}$ Zouk: música com origem nas Antilhas com forte presença em Cabo Verde desde a década de 1980, a partir do êxito internacional do grupo Kassav.

7 Colazouk/Kolazouk: adaptação por músicos cabo-verdianos do zouk, numa fusão com a coladeira de Cabo Verde.

NOGUEIRA, G. A. Exaltar a tradição e ser contemporâneo: a conversão do estigma em emblema no batuku de Cabo Verde. Música Popular em Revista, Campinas, ano 6, v. 1, p. 185-206, jan.- 
encontrava ainda distante do batuku com que se consagraria) e toca baixo também no quinteto Capeverdeans Jazz Band. Neste efémero grupo, o contacto com músicos como Djinho Barbosa e Ney di Belinha (Ney Bettencourt) terá influenciado o seu percurso, abrindo-lhe os horizontes musicais. Nessa época, Pantera passa um período no Brasil, onde, na Bahia, frequenta formações de percussão com grupos como Muzenza, Ilê Ayé e Olodum. Embora já tivesse tido uma composição gravada pelo célebre grupo Os Tubarões, no seu último disco (de 1994) antes de se desintegrar, é a partir de finais da década de 1990 que Pantera começa a se destacar com as composições que reelaboram o batuku. Nessa altura, colaborava com a coreógrafa portuguesa Clara Andermat, tendo participado de dois espetáculos dessa companhia, como músico, compositor, e assistente da direção musical. (NOGUEIRA, 2016, p. 408-410).

As criações de Orlando Pantera consistem em utilizar na guitarra os padrões rítmicos do batuku, com letras que falam do quotidiano do interior de Santiago, hábitos, formas de relacionamento, entre outros elementos que compõem um imaginário ligado ao mundo rural e a essa ilha. Há também nas suas letras referências ao próprio batuku tradicional. Por exemplo, quando diz "Abo ê tchabeta, ami ê rapikadu"8 (Você é a tchabeta - o ritmo/o som; eu sou o clímax, ponto alto do batuku - tradução da autora) no tema "Resposta". Ou ao referir o próprio momento em que se projeta: "Batuko stá na moda" (O batuku está na moda), em "Batuko". Numa entrevista concedida possivelmente a uma rádio, que circulou em Cabo Verde num CD pirata, intercalada com trechos do próprio músico a cantar os seus temas e a acompanhar-se ao violão, o compositor afirma:

A pesquisa que faço reproduz o que eu vejo, não só o que eu ouço; reproduz aquela pessoa, homem ou mulher, que chora, que está com o pé no chão, que salta de alegria, então tenho que tirar o seu olhar, seu cabelo, sua raiva, igual àquele homem do interior de Santiago, pois estou a falar dele, estou a imitálo; então procuro ir o mais longe que posso em reproduzir o que vejo, o que ouço e o que sinto. (PANTERA, s.d. [ca. 2000]).

\footnotetext{
8 Tchabeta é um termo polissêmico sendo um dos seus significados o som polirrítmico produzido pelas percussionistas. Rapika, por extensão rapikadu, é o clímax de uma sessão de batuku, que normalmente vai num crescendo.
}

NOGUEIRA, G. A. Exaltar a tradição e ser contemporâneo: a conversão do estigma em emblema no batuku de Cabo Verde. Música Popular em Revista, Campinas, ano 6, v. 1, p. 185-206, jan.- 
Outros artistas com a mesma proposta de reescrita do batuku irão apresentar nos seus trabalhos temas semelhantes a estes. São habituais - embora não exclusivas a esses temas - letras a falar de nha rubera (minha ribeira); a chuva esperada e a água a correr quando chove ou, pelo contrário, a seca; a criação de gado; alusões à tabank $a^{9}$; oposição capital $\mathrm{x}$ interior da ilha; poial (mureta de pedra no exterior das casas rurais); a sulada (faixa de tecido com várias finalidades usada pelas mulheres no meio rural); a stera (altar montado em honra de um defunto, na casa deste); a sementeira; a bênção dos mais velhos; aspetos relacionados com o noivado e casamento... Há todo um conjunto de elementos que compõem um imaginário ligado ao mundo rural que é invocado na criação das letras dessas músicas.

Por exemplo, Mayra Andrade, que inicia aos 16 anos a sua carreira musical, nesse período em que o batuku passa a ser interpretado em moldes urbanocontemporânos, compõe por sua vez temas que fogem às suas vivências pessoais filha de um militar com posição de chefia intermédia nos primeiros anos do pósindependência, o contexto em que se insere é urbano e privilegiado do ponto de vista socioeconómico. Por outro lado, entre a infância e a adolescência, viveu com a família em diferentes países (Senegal, Angola, Alemanha). Nesses locais, estudou sempre em escolas francesas.

Nas produções seguintes, os temas se universalizam, ainda que continuem presentes nos álbuns Stória Stória (2009) e Studio 105 (2010) temas ligados a Santiago "fundo". (cf. CIDRA, 2011, p. 280, 364, para os significados de "fonte" "raiz" e "fundo"). No álbum de 2019, Manga, "Festa Sto Santiago" é a única composição a evocar esse imaginário rural/tradicional, mencionando um prato tradicional (Fijon xarém ku bódi - feijão com milho triturado e carne de bode), o grógu (aguardente), a gaita (acordeão que tradicionalmente acompanha o funaná) e mesmo um elemento que faz parte dos estereótipos do badiu como figura violenta: o fato de portar uma faca oculta na roupa. Referindo-se à imagem do badiu, Cidra aponta:

\footnotetext{
9 Tabanka: trata-se de um tipo de associação popular mutualista que, entre outras atividades de sociabilidade e entreajuda, festeja os santos católicos com uma série de rituais que envolvem desde rezas a dramatizações e um desfile com cantos e dança. Reprimida no período colonial (SEMEDO; TURANO, 1997),passou a ser valorizada após a independência de Cabo Verde como um elemento cultural do país.
}

NOGUEIRA, G. A. Exaltar a tradição e ser contemporâneo: a conversão do estigma em emblema no batuku de Cabo Verde. Música Popular em Revista, Campinas, ano 6, v. 1, p. 185-206, jan.- 
Ao estatuto de detentores de formas culturais ancestrais da nação, juntam-se enunciados racializados como os da ausência de "civilização", de "educação". O badiu é frequentemente retratado como iletrado, ignorante, violento, temperamental, ruidoso e pouco "refinado" nos seus modos de ser. A imagem do homem cabo-verdiano usando faca repousa, na imaginação dos cabo-verdianos, no homem badiu. (CIDRA, 2011, p. 67). ${ }^{10}$

No seu disco de estreia, Mayra apareceu com três batukus, dois do já referido Orlando Pantera ("Lapidu na bo" e "Dispidida") e "Lua", de Princezito, outro nome de destaque neste contexto a que farei referência adiante. Da autoria da própria Mayra, há também um batuku, "Nha Sibitchi”, e a canção "Mana”, que em jeito de bossa nova traz como personagem uma rapariga que sai do interior para a capital com o objetivo de arranjar marido, para desgosto dos pais. No repertório de Navega (2006), há ainda "Nha nobreza" (Betú), com o dilema da virgindade de uma adolescente em meio à paisagem rural de S. Domingos, município próximo da Praia. Em todas essas composições a ambiência é do Santiago rural, com latas d'água a equilibrar-se na cabeça das mulheres, rezas e finasons, a missa de domingo, o próprio sibitchi11. Questionada sobre o porquê de contar histórias que não são do seu mundo - de jovem urbana e cosmopolita, vivendo na Europa -, mas sim ligadas ao meio rural, Mayra afirmava, na época:

Por enquanto, não apareceu um tema urbano que me inspirasse uma música. Inspirou-me mais falar da mulher do pescador (em Navega), da superstição, daqueles rumores dos meios pequenos, que aparecem em "Nha Sibitchi". Em Cabo Verde, mesmo quem vive na cidade tem acesso ao rural quase quotidianamente, pois os dois meios acabam por se misturar. O rural é muito próximo da cidade. Apesar de ter vivido fora do país, também vivi em Cabo Verde; na minha infância, ia passear em Rui Vaz, cresci a ver batucadeiras... Algumas das personagens de "Nha Sibitchi" são fictícios, outros são reais. São temas que têm uma energia, um brilho, um charme que me inspiram realmente. (ANDRADE, entrevista à autora, 2006).

A discografia de Tcheka, por sua vez, traz um conjunto de histórias sobre situações vividas no campo. Natural de Ribeira da Barca, localidade piscatória no interior de Santiago, a partir dos nove anos Tcheka tem de aprender a tocar guitarra,

\footnotetext{
${ }^{10} \mathrm{Na}$ sua tese, este autor mostra como, além de ser uma imagem atribuída aos badius como forma de racialização, desde o período colonial, a atitude violenta é assumida pelos próprios como parte das construções identitárias de masculinidade. (cf. CIDRA, 2011, p. 324-327). Pesquisando a imprensa cabo-verdiana ao longo do tempo, encontra-se com muita frequência, nas descrições de festas populares ou festivais de música, a menção a distúrbios violentos ou à ausência destes, sendo esta última situação normalmente merecedora de destaque, o que indica a sua excepcionalidade.
}

11 Sibitchi: amuleto feito de contas, usado junto ao corpo, bastante comum em Cabo Verde.

NOGUEIRA, G. A. Exaltar a tradição e ser contemporâneo: a conversão do estigma em emblema no batuku de Cabo Verde. Música Popular em Revista, Campinas, ano 6, v. 1, p. 185-206, jan.jul. 2019. 
assim como os irmãos, pois o pai, Nho Raul Andrade (1927-2005), ao violino, liderava um grupo musical familiar baseado nos instrumentos de corda, que constituía um reforço no orçamento doméstico, animando festas e bailes pela região. Nesse sentido, e porque nessas ocasiões o repertório habitualmente incluía mornas, coladeiras e sambas, a formação musical de Tcheka é bastante eclética. Mas ainda adolescente manifesta preferência pelas músicas de Santiago, o batuku principalmente, também marcante na sua infância, já que omnipresente na vivência dos habitantes de Santiago e indispensável em todas as comemorações.

Tcheka trabalhava como operador de câmera na televisão pública de Cabo Verde e por vezes atuava entre amigos em bares da cidade da Praia, quando começou a ser notado. A sua discografia inicia-se em 2001, com um tema no CD Cap Vers l'Enfant II, iniciativa francófona de objetivo filantrópico. Em 2002, faz parte, com três temas, do já referido projeto coletivo Ayan!. Na mesma época, temas seus são gravados pela cantora Lura, quando esta se volta para o batuku. Em 2003, sai o seu primeiro álbum a solo, Argui! (Ergue-te!). Segue-se Nu Monda (algo como “Vamos capinar, mondar"), em 2005, mesmo ano em que foi premiado no concurso Découverte Musiques du Monde, da Radio France International. Em 2005 participa também do CD Praia-Dakar-Conexões. Em 2007 vem Lonji (Longe) e em 2011 Dor de Mar. Cantor e compositor, Tcheka baseia o seu trabalho, tal como Pantera, na transposição para as cordas do violão do ritmo do batuku, enquanto as suas letras discorrem sobre as histórias de homens e mulheres do interior de Santiago, com suas crendices, as condições de trabalho, o namoro e os ciúmes, a luta pela subsistência, letras que são como pequenos contos a retratar esse quotidiano rural.

Vadú (1977-2010) é outro exemplo de cantor e compositor inserido nessa vaga de reelaboração do batuku em se pode encontrar um frequente uso dos elementos de alusão à tradição e à ruralidade. Na sua curta carreira, gravou dois álbuns a solo, Nha raís (minha raiz), de 2004 e Dixi rubera (descer pela ribeira), editado em 2007, mas as suas primeiras gravações encontram-se em Ayan! (2002). Nascido na Praia e sobrinho de dois nomes que fizeram história na música de Cabo Verde nos anos 1980, Zezé di Nha Reinalda e Zeca di Nha Reinalda, Vadú estudou violão com Orlando Pantera, por volta dos 13 anos, e dos 17 aos 20 esteve a estudar em Cuba. De 
regresso a Cabo Verde, o seu contacto com a música e artistas mais experientes dá-se no Quintal da Música, espaço de música ao vivo onde trabalhava como técnico de som. É nessa altura que começa a compor. Dixi rubera já no título assinala o ambiente rural. A ribeira, na ausência de rios perenes, é um elemento forte no imaginário caboverdiano ${ }^{12}$ e não por acaso várias localidades, nas diferentes ilhas, são nomeadas com referência à ribeira junto à qual se situam - Ribeira da Barca, Ribeira da Prata, Ribeira Brava, Ribeira Grande, entre outras.

As enxurradas no tempo das chuvas, a produção do grogu/grogue, o florescer do milho - símbolo de comida -, práticas agrícolas como a monda, o próprio batuku, a tabanka e outras manifestações culturais tradicionais são exemplos eloquentes da presença do imaginário rural/tradicional nas letras de Vadú. Em "Lá fora", composição da sua autoria, a oposição entre a capital e o interior (identificado habitualmente como "fora") serve pera valorizar esses elementos:

É bunito sim, horas ki nu odja nos tradison finkado na tchon
Tabanka nha genti, batuku, funaná
Pa ka kaba nunca mas, e pa fika dentu nos korason.
Horas ki nu bai la fora
Ki nu odja batukaderas na terero ta da ku torno
Rapazinhos di Praia, nha genti, tudo ta rodiado...13 (VADÚ, 2007).

Nesse grupo de artistas que ganha visibilidade por volta de 2000, Princezito, natural do Tarrafal, seria aquele mais próximo das referências mais concretas no que diz respeito ao batuku e ao finaçon tradicionais, pois desde criança conviveu de perto com uma das mestras nessa arte, Nha Bibinha Cabral, e terá começado bem cedo a criar os seus próprios versos, estimulado por uma tia. (PRINCEZITO, entrevista à autora, 2010). Contudo, é dentre estes artistas provavelmente aquele cujas letras apresentam as temáticas mais universais. É, por

\footnotetext{
12 Sobre a relação do homem com a natureza em Cabo Verde e a construção de um imaginário que relaciona a seca com a identidade, ver Lobo, 2012. Também aqui, tal como no tema deste artigo, constata-se uma mudança de algo que era negativo para algo valorizado. No caso, a natureza impiedosa passa a ser encarada como paisagem a ser preservada e valorizada. Suas características passando a ser encaradas como "valiosas não tanto como recursos, mas como reservatórios de valor dignos de serem vistos e admirados." (LOBO, 2012, p. 87).

13 É bonito sim, quando vemos a nossa tradição firme / Tabanka, minha gente, batuku, funaná / Para nunca acabar e para ficar no nosso coração / Quando se vai para o interior, e vemos batukaderas no terreiro, a dançar / Juntam-se as pessoas da Praia (tradução da autora).

NOGUEIRA, G. A. Exaltar a tradição e ser contemporâneo: a conversão do estigma em emblema no batuku de Cabo Verde. Música Popular em Revista, Campinas, ano 6, v. 1, p. 185-206, jan.jul. 2019.
} 
outro lado, aquele que está a levar os versos do finason para o suporte escrito, tendo publicado em 2015 o livro Antigu Pensamentu.

Vários outros compositores-intérpretes a produzir nesta linha do batuku contemporâneo poderiam ser invocados, mas a título de exemplo ficamos com uma das mais recentes revelações da música cabo-verdiana, Élida Almeida, que aos 22 anos lançou, no final de 2014, o seu primeiro álbum e menos de um ano depois venceu o prémio Découvertes, da Radio France Internationale (RFI). Em 2017 editou o seu segundo álbum. Embora não associada especificamente ao batuku, mas gravando este ritmo entre outros nos seus discos, Élida Almeida encaixa-se nesta reflexão. Cresceu a ouvir músicas de Cabo Verde (Bulimundo, Ildo Lobo) mas também Scorpions e os brasileiros da vaga sertaneja (Leandro e Leonardo, Zezé de Camargo e Luciano). (ALMEIDA, entrevista à autora, 2015). Começa a cantar no coro da igreja e, mais tarde, enquanto faz os estudos universitários na cidade da Praia, acaba por ser "descoberta" pelo produtor Djô da Silva ${ }^{14}$. Nas letras de Élida Almeida, o rural surge com grande nitidez, e a letra de um dos temas de maior sucesso do seu primeiro álbum, “Lebam ku bo" (leva-me contigo), descreve os preparativos de um casamento.

\author{
Nha mai dja flam mé ta dam boi \\ nha madrinha fla ma tambi mé ta dam sofá \\ vizinhos tudo dja ka limpa boroncera \\ ta djobi panela três pé pa kucia mandioca \\ nha pai dja fla mé ta dam 2 kanteru di orta \\ nha avo dja manda flam pa nbá toma quarta midjo \\ ma nhas minis, ma nhas minis \\ dja ká prepara ses bistidu pes cirbim dama ${ }^{15}$ (ALMEIDA, 2014)
}

Questionada sobre em que medida essa letra espelha as suas vivências, responde que é "exatamente" assim.

Em Santa Cruz quando uma pessoa casa é assim como falo na música, a mãe tem de dar isso, o pai ter de dar isso, a madrinha tem de dar aquilo [...]

\footnotetext{
${ }^{14}$ Djô da Silva foi quem lançou a carreira internacional de Cesária Évora, no início da década de 1990, e tem sido, nos últimos 20 anos, responsável pelo lançamento de vários novos artistas, incluindo os aqui referidos Princezito, Tcheka e Lura.

${ }^{15}$ Minha mãe disse que me dá um boi/ Minha madrinha disse que dá o sofá / Os vizinhos limpam o terreno / Procuro uma panela de três pés para cozinhar mandioca / Meu pai disse que oferece dois canteiros da horta / Minha avó mandou avisar para ir buscar milho / Minhas amigas preparam seus vestidos para serem damas... (tradução da autora).

NOGUEIRA, G. A. Exaltar a tradição e ser contemporâneo: a conversão do estigma em emblema no batuku de Cabo Verde. Música Popular em Revista, Campinas, ano 6, v. 1, p. 185-206, jan.- 
todas as mulheres de Santa Cruz, e não só, acho que todas as mulheres têm, não sei como é que se chama, essa 'paranoia' de casar um dia, e nós em Santa Cruz sonhamos em casar daquele jeito, crescemos a ver a nossa mãe, a nossa avó, e também queremos casar da mesma maneira. (ALMEIDA, entrevista à autora, 2015).

O disco é "como uma autobiografia", diz a cantora e compositora, revelando que as letras contam histórias da mãe, do irmão, dela própria, que assume uma postura conservadora de seguir a tradição das localidades rurais de Santiago. Esse apego a padrões e valores de um modo de vida tradicional-rural numa compositora de 22 anos, estudante universitária na área da comunicação e multimídia e a viver na capital não deixa de surpreender, quando costuma ser um tema de reflexão os efeitos da globalização ou das interferências dos hábitos urbanos no meio rural, pela via do êxodo rural ou dos meios de comunicação.

Outro tema da sua autoria em que a ruralidade é exaltada é "Nhu Santiagu" (além de ser o nome da ilha, Santiago designa na linguagem popular a região que corresponde ao município de Santa Cruz), verdadeira declaração de amor à terra natal. Toda a letra desta composição poderia ser citada como exemplo, mas fiquemos com estes versos em que a compositora afirma que, quando fica muito tempo distante desse lugar, "korason ta pertam / Pamo lá ki sta nha fonti di inspirason / Nha biku la ki sta interadu". ${ }^{16}$ No seu segundo álbum, Kebrada, este tipo de temática continua presente, particularmente nos temas "Sapatinha - Nha Minineza” (Minha Infância), “Bersu Doru” (Berço de ouro), em que alude à tabanka.

Refira-se que também os videoclipes de divulgação das músicas destes artistas citados são concebidos de forma a reforçar a ideia de pertença ao interior de Santiago, com paisagens em que a vegetação, cenas de trabalho na agricultura, animais associados a esse espaço como cabras, bois e asnos, objetos do uso quotidiano como o pilão, o vestuário, atitudes e gestos, entre outros pormenores, são convocados para formar um cenário a representar com minúcia esse mundo ruraltradicional. Não se aprofunda aqui este aspeto porque há material e reflexões possíveis suficientes para um artigo específico sobre este tema. Tal como Cidra (2011, p. 274), que assinala o perfil etnográfico da abordagem de Orlando Pantera aos temas

\footnotetext{
${ }^{16}$ Sinto o coração apertado / Porque é lá que está a minha fonte de inspiração / É lá que o meu umbigo está enterrado (tradução da autora).

NOGUEIRA, G. A. Exaltar a tradição e ser contemporâneo: a conversão do estigma em emblema no batuku de Cabo Verde. Música Popular em Revista, Campinas, ano 6, v. 1, p. 185-206, jan.- 
do mundo rural de Santiago, Edward Akintola Hubbard (2011), que trabalhou sobre a iconicidade no movimento de reescrita do batuku, chama a atenção para o papel de "antropólogo nativo" que este compositor assume quando trabalha sobre esta temática, e entende que esta apropriação da antropologia e da observação participante foi crucial para forjar uma identidade intelectual para o batuku contemporâneo e para os badius em geral (HUBBARD, 2011, p. 135). Essa atitude, aponta este autor, afasta o compositor daquilo a que ele se refere. O homem rural de Santiago é objeto de "pesquisa", e referido por Pantera na entrevista como "eles" ou "aquelas pessoas", o que, como nota o autor, assemelha-se ao tom característico do antropólogo ocidental, ou seja, há uma "distância científica” assumida.

Ao mesmo tempo, o interior de Santiago é imaginado como repositório de valores ancestrais do badiu e "mesmo quando o badiu di fora é uma vítima da economia global moderna, ele continua a ser o feliz guardião da linguagem badia e da 'tradição'” (HUBBARD, 2011, p. 138). Assim, para manter uma expressão badia "pura", o batuku contemporâneo, contaminado por elementos do mundo urbano, deve sempre manter uma conexão com as suas raízes, com o solo nativo a partir do qual brotou. Tal visão pode justificar essa presença forte da temática ligada ao imaginário rural-tradicional nas composições desse grupo de compositores.

Estas ideias estão em sintonia com as de Cidra (2011, p. 280), quando este refere que as as ideias de "fonte" e "raiz" "foram projetadas para o interior rural de Santiago (...) a sua população camponesa foi construída como simbolizando a ancestralidade dos cabo-verdianos e da nação cabo-verdiana, a autenticidade cultural e humana e, sobretudo, a "resistência ao colonialismo" num momento de produção política de diferença relativamente ao regime colonial português.

Por sua vez, Ribeiro (2012, p. 167), trabalhando no contexto da comunidade cabo-verdiana imigrada em Portugal, em particular nos bairros periféricos de Lisboa, observa que o batuku é associado “à própria identidade caboverdiana" e "adquire um valor simbólico único enquanto ícone da "caboverdianidade", embora aponte a sua marginalidade mesmo em tempos pós-coloniais face aos outros géneros musicais cabo-verdianos (2012, p. 166). 
Nessas circunstâncias e para essas pessoas ele simboliza o lado africano de Cabo Verde e, na visão ontológica e essencialista que tão cara é aos discursos da identidade e à retórica das origens, o verdadeiro representante dessa cabo-verdianidade.

Paradoxalmente é nesta altura que a sua condição de marginalidade se transforma em privilégio: o batuku configura agora para estes caboverdianos um escudo de diferenciação e, para as mulheres que o desempenham e que o representam, uma oportunidade de ascensão social, de reconhecimento e distinção. (RIBEIRO, 2012, p. 167).

Embora Ribeiro trabalhe sobre a prática do batuku tradicional, não o recriado pelo grupo de compositores e intérpretes aqui em questão, que por volta do ano 2000 empreenderam a transformação do batuku num estilo musical do contexto urbano e contemporâneo, esta afirmação vai também na linha do que a eles se aplica, a conversão do estigma em emblema, o que evidencia que isso ocorre nas suas duas vertentes.

\section{Outras geografias, as mesmas questões}

Deixando de lado a análise académica e buscando a visão de um criador, pode-se encontrar em Ondjaki, quando fala da infância na Luanda dos anos 1980 um lugar cheio de estórias urbanas, onde as crianças não falavam o mesmo quimbundo dos avós - um caminho para a compreensão dessa pulsão dos artistas badius pelo imaginário rural-tradicional.

[...] os autores africanos que eu lia, ou pelo menos assim eu os li, iam murmurando verdades suaves: que a literatura se fazia dos lugares, das geografias, das cores e das gentes, mas que os lugares eram, também, coisas internas; que o escritor, africano ou outro, podia falar do seu lugar e partir das suas tradições para se reinventar na sua ficção, mas não esquecendo que no ato sagrado da escrita as geografias que mais gritam são as de dentro. (ONDJAKI, 2008, p. 52).

Por sua vez, ao analisar a Córsega, Jean-Louis Fabiani refere que muitas vezes, ao opor-se tradição e modernidade, ignora-se a capacidade que têm formas antigas de se adaptarem às novas condições históricas e, ao mesmo tempo, a "novidade radical que a reivindicação de comportamentos tradicionais e autênticos pode constituir". Segundo este autor, a lógica da inversão dos estigmas permite explicar a maior parte dos posicionamentos reivindicatórios em matéria cultural: “a 
reaquisição (riacquistu) de uma cultura perdida ou denegada é empreendida" e, assim, as formas de expressão que se julga terem sido desvalorizadas pela cultura dominante são objeto de reabilitação e de investimento (FABIANI, 2003, s.n.).

Canclini por sua vez, flexibiliza o entendimento destas questões, referindo, a propósito da questão de pertença, que nas sociedades modernas um indivíduo pode participar de diversos grupos, integrando-se "sincrónica e diacronicamente a vários sistemas de práticas simbólicas: rurais e urbanas, suburbanas e industriais, microssociais e dos mass media" (CANCLINI, 2008, p. 220), ideia que de alguma forma esvazia o questionamento do qual se partiu para esta reflexão: o de eventualmente haver uma contradição entre ser urbano e jovem e voltar-se para a raiz e o antigo.

Featherstone (1997, p. 145) lembra que na tradição sociológica o termo local e seus derivados localidade e localismo são habitualmente associados a "um espaço determinado, limitado, com seu conjunto de relacionamentos sociais estreitos, baseados em fortes laços de parentesco e tempo de duração da residência", pressupondo uma identidade cultural "homogénea e integrada [...] duradoura e única". Este autor aponta por outro lado dois pressupostos que influenciaram as pesquisas sociológicas sobre as localidades e comunidades: o primeiro, baseado nos modelos de mudança social do século XIX, "em que o passado era encarado como algo que implicava relacionamentos sociais mais simples, mais diretos e fortemente unidos", levando a descrições nostálgicas de um mundo perdido face aos modos de vida da metrópole moderna; o segundo, com base na antropologia, valorizando o trabalho etnográfico para se obter descrições da particularidade de pequenas cidades ou aldeias. Entretanto, refere, tornou-se evidente a necessidade de delinear as fronteiras da localidade, a partir da compreensão de que qualquer comunidade isolada estava conectada com sociedades nacionais. "Não é proveitoso encarar o global e o local como dicotomias separadas no espaço e no tempo. Ao que tudo indica, os processos de globalização e localização estão inextricavelmente ligados na atual fase" (FEATHERSTONE, 1997, p. 144).

Voltando às questões apresentadas no início deste artigo, na tentativa de compreender as motivações daqueles jovens compositores para privilegiarem as 
temáticas ligadas ao imaginário rural - questão de mercado, apostando no exotismo do terra-terra; questão identitária, a salientar o apego ao local de origem; ser urbano ou ser rural em Cabo Verde nos dias de hoje -, as palavras de Featherstone, se não chegam a respondê-las, servem de pistas para reflexão, não se excluindo que as eventuais conclusões sejam uma mescla de várias possibilidades, tendo em conta em particular a possibilidade de múltipla inserção de um mesmo artista em âmbitos distintos mas só aparentemente antinómicos entre si e, ao mesmo tempo, a interpenetração campo-cidade: rurbanos, pela ocupação do espaço, pelos costumes e pelas relações. E é a própria Élida Almeida que canta em "Ilia Mundu": "Pa ka pergunta-m m’é di ki ilia / Di ki rubera, di ki kutelu mi é..." (Não me pergunte de que ilha eu sou, de que ribeira, de que morro eu sou), para responder alguns versos adiante: "Nha ilia é mundu" (minha ilha é o mundo).

\section{Referências bibliográficas}

BOURDIEU, Pierre. O poder simbólico. Lisboa: Difel, 1989. Tradução de Fernando Tomaz.

CABO VERDE/Instituto Nacional de Estatísticas. Censo 2010. Disponível em: www.ine.cv. Acesso em 18 Nov. 2015.

CARNEIRO, Maria José. Ruralidade: novas identidades em construção", Estudos Sociedade e Agricultura, outubro 2014 vol. 22, número 2.Disponível em: http://r1.ufrrj.br/esa/V2/ojs/index.php/esa/article/view/135. Acesso em 08 Nov. 2015.

CIDRA, Rui. Música, poder e diáspora. Uma etnografia e história entre Santiago, Cabo Verde, e Portugal. Tese (Doutoramento em Antropologia das Migrações, Etnicidade e Transnacionalismo). Universidade Nova de Lisboa, 2011.

DELGADO, Manuel. Apontamento - Batuco. De Rabidantibus, 2009.

DUARTE, Dulce Almada. Torno finkado, cabeta rapicadu e batuku. Mujer, julho de 1982.

FABIANI, Jean-Louis. A Córsega ou as servidões da autenticidade, Sociologias, número 9, Porto Alegre, Jan./Jun. 2003. Disponível em: http:/ / www.scielo.br/scielo.php?script=sci_arttext\&pid=S1517-45222003000100013. Acesso em 16 Nov. 2015. Tradução de Sonia Taborda.

NOGUEIRA, G. A. Exaltar a tradição e ser contemporâneo: a conversão do estigma em emblema no batuku de Cabo Verde. Música Popular em Revista, Campinas, ano 6, v. 1, p. 185-206, jan.- 
FEATHERSTONE, Mike. O desmanche da cultura. São Paulo: Studio Nobel, 1997.

FURTADO, Cláudio. A transformação das estruturas agrárias numa sociedade em mudança: Santiago, Cabo Verde. Praia: Instituto Caboverdiano do Livro e do Disco, 1993.

GARCÍA CANCLINI, Nestor. Culturas Híbridas. 2a edição. São Paulo: Edusp, 2008. Tradução de Heloísa P. Cintrão/Ana Regina Lessa.

HALL, Stuart. A identidade cultural da pós-modernidade. 10ª ed. Rio de Janeiro: DP\&A 2005 [1992]. Tradução de Tomaz Tadeu da Silva/Guacira Lopes Louro.

HUBBARD, Edward Akintola. Creolization and Contemporary Pop Iconicity in Cape Verde. Tese (Doutoramento em Antropologia). Harvard University, Cambridge, Massachusetts, 2011.

HURLEY-GLOWA, Susan, Batuko and Funana: Musical Traditions of Santiago, Republic of Cape Verde. Tese (Doutoramento em Música). Brown University, 1997.

KATCHÁS (Carlos Alberto). Funaná, a maior conquista. Tribuna, dezembro de 1986, p. 13.

LOBO, Andréa. Do feio ao belo. Aridez, seca, "patrimônio natural" e identidade em Cabo Verde. In: Sansone, Livio (org.) Memórias da África: patrimônios, museus e políticas das identidades. Salvador: ABA/EDUFBA, 2012, 67-90.

NOGUEIRA, Gláucia. Batuku de Cabo Verde. Percurso histórico-musical. Praia: Pedro Cardoso Livraria, 2015.

Cabo Verde \& a Música. Dicionário de Personagens. Lisboa: Campo da Comunicação, 2016.

ONDJAKI. As Raízes do Arco-íris (Ou: O camaleão que gostava de frequentar desertos). In: PADILHA, Laura Cavalcante; RIBEIRO, Margarida Calafate (orgs.). Lendo Angola. Lisboa: Edições Afrontamento, 2008, p. 51-52.

PRINCEZITO. Antigu Pensamentu, Praia: Editorial Sotavento, 2015.

RIBEIRO, Jorge Manuel Castro. Inquietação, memória e afirmação no batuque: música e dança cabo-verdiana em Portugal. Tese (Doutoramento em Música). Universidade de Aveiro, 2012. Disponível em: https:/ / ria.ua.pt/bitstream/10773/7559/1/246480.pdf. Acesso em 24.04.2019.

SEMEDO, Carla. 'Mara sulada e dã ku torno': performance, gênero e corporeidades no Grupo de Batukadeiras de São Martinho Grande (Ilha de Santiago, Cabo Verde). 
2009. Dissertação (Mestrado em Antropologia Social). Universidade Federal do Rio Grande do Sul, Porto Alegre, 2009. Disponível em:

https://lume.ufrgs.br/handle/10183/16227. Acesso em 24.04.2019.

SEMEDO, José Maria; TURANO, Maria R. Cabo Verde. O ciclo ritual das festividades da tabanca. Praia: Spleen Edições, 1997.

SILVA, Tomé Varela da. Ña Bibiña Kabral - Bida y Obra, col. Tradições Orais de Cabo Verde, Praia: ICL, 1988a.

$1988 b$.

. Finasons di Ña Nasia Gomi, col. Tradições Orais de Cabo Verde, Praia: ICL,

Na Gida Mendi - Simenti di Onti na con di mañan, col. Tradições Orais de Cabo Verde, Praia: ICL, 1990.

SILVA, António Leão Correia e. Histórias de um Sahel Insular. Praia: Spleen Edições, 1995.

TOLENTINO, Corsino. Rurbanos. A Semana, Praia, nº 25, p. 2, 31.01.1992.

\section{Documentos sonoros}

ALMEIDA, Élida. Ora doci ora margos. Lusafrica, 2014. CD. . Kebrada. Lusafrica, 2917. CD.

ANDRADE, Mayra. Navega, Sony BMG, Paris, 2006. CD. . Stória stória, Sony Music, Paris, 2009. CD. . Studio 105, Sony Music, Paris, 2010. CD. . Manga, Sony Music, Paris, 2019. CD.

PANTERA, Orlando. Sem título, não editado, sem data. CD.

TCHEKA. Argui! Harmonia, 2003. CD. . Nu monda. Harmonia, 2005. CD+DVD. . Lonji, Harmonia, 2007. CD.

VADÚ. Nha Raiz. Praia Records, 2004. CD. 
Dixi Rubera. AV Produções, 2007. CD.

VVAA. Cap Vers l’Enfant II. Roger Brattin, 2001. CD.

Ayan! CD, Praia, Praia Records, 2002. CD.

Praia-Dakar Conexões, Harmonia, 2005. CD.

\section{Entrevistas}

Élida Almeida, Praia, Cabo Verde, maio 2015.

Mayra Andrade, Praia, Cabo Verde, julho 2006.

Princezito, Praia, Cabo Verde, abril, 2010. 